\title{
Questioning the efficacy of 'gold' open access to published articles
}

Cite this article as: Fredericks S (2015) Questioning the efficacy of 'gold' open access to published articles.

Nurse Researcher. 22, 6, 8-10.

Date of submission: December 16 2014. Date of acceptance: January 292015.

Correspondence to sfrederi@ryerson.ca

Suzanne Fredericks RN, PhD, is an associate professor at Ryerson University, Toronto, Canada

\section{Peer review}

This article has been subject to double-blind review and has been checked using antiplagiarism software

\section{Author guidelines} journals.rcni.com/r/ nr-author-guidelines

\section{Abstract}

Aim To question the efficacy of 'gold' open access to published articles.

Background Open access is unrestricted access to academic, theoretical and research literature that is scholarly and peer-reviewed. Two models of open access exist: 'gold' and 'green'. Gold open access provides everyone with access to articles during all stages of publication, with processing charges paid by the author(s). Green open access involves placing an already published article into a repository to provide unrestricted access, with processing charges incurred by the publisher.

Data sources This is a discussion paper.

Review methods An exploration of the relative benefits and drawbacks of the 'gold' and 'green' open access systems.

Discussion Green open access is a more economic and efficient means of granting open access to scholarly

\section{Introduction}

Publishing is the act of making available through the written word one's philosophies, observations and behaviours. In academia, publishing is a required behaviour and is most often used as an outcome measure to evaluate people's levels of productivity in a discipline, as well as their effect on the larger global community in promoting and sharing new knowledge. Promotion and tenure are typically based on an academic's ability to publish. Publishing results in the general sharing of ideas and new knowledge with researchers, lay individuals, clinicians and policy creators. It also assists in enhancing the prestige of authors, as well as supporting grant applications and other forms of financial reward, such as stipends. literature but a large number of researchers select gold open access journals as their first choices for manuscript submissions. This paper questions the efficacy of gold open access models and presents an examination of green open access models to encourage nurse researchers to consider this approach.

Conclusion In the current academic environment, with increased pressures to publish and low funding success rates, it is difficult to understand why gold open access still exists. Green open access enhances the visibility of an academic's work, as increased downloads of articles tend to lead to increased citations.

Implications for research/practice Green open access is the cheaper option, as well as the most beneficial choice, for universities that want to provide unrestricted access to all literature at minimal risk.

Keywords Open access, self-archiving, publishing, repository, scholarly literature, dissemination

\section{Background}

On average, 2.5 million academic articles are published every year worldwide (Gargouri et al 2010). However, not all articles are readily available to the global research community. Publishers have contributed to this lack of availability by requiring institutions and individuals to pay subscription fees to access articles. Institutions, as well as individuals who are not financially able, tend not to invest in access, limiting the number of articles read. Thus, the sharing of ideas and new knowledge through publishing is limited to those who can afford to pay (Swan 2006). Even if an institution is capable of paying for access, no single organisation can financially afford to read all the articles that 
are released, resulting in articles not achieving their full impact in terms of usage and citations (Gargouri et al 2010).

This has led to a call for an alternative model of publishing in which all producers, distributors and consumers of knowledge have free or open access to all articles published (Price 2012). This paper will present two models for open access publishing and argue in favour of one approach in terms of relevance and feasibility.

\section{Open access}

Open access is unrestricted access to academic, theoretical and research literature that is scholarly and peer-reviewed (Gargouri et al 2010). The word 'open' denotes the availability of literature free of cost to the reader. Thus, literature that is open access tends to be cited more often than literature that is not (Gargouri et al 2010).

There is general agreement that any form of open access publishing strengthens academia, as it enhances productivity, increases the recognition and dissemination of findings and end products, and removes cost-related barriers to accessing scholarly work (Swan 2006, MacMillan et al 2014). More than 160 institutions worldwide have now mandated open access publishing. A number of research institutions and universities, including Harvard, Stanford, Toronto, McGill, MIT and Oxford, have policies that require any papers written by their employees to be made immediately available for free to the general public (Straumsheim 2013). These policies are similar to ones created by the US National Institutes of Health, the Wellcome Trust, the Canadian Institutes of Health Research (Straumsheim 2013) and other government funding agencies, which are moving towards mandatory open access publishing for all works they fund, arguing that research funded by taxpayers should be made publicly available as soon as possible. Moreover, in 2008, the council of the European University Association, of which 850 universities in 47 countries are members, unanimously recommended that all research associated with European universities be made available through some form of open access (Straumsheim 2013).

For papers to be disseminated in open access forums, two models are available: 'gold' and 'green'.

\section{Gold open access}

'Gold' open access publishing was the first form of open access established (Mabe 2012). The colour refers to how an article can be archived. Gold relates to complete open access, which means researchers can archive the published article in its entirety.
As a result, all materials can be accessed by institutions and individuals without any restrictions.

Under the gold open access model, all publishing fees - the 'article processing charge' (APC) are charged directly to the author and the fee varies depending on the journal: they can average from US $\$ 1,500$ to more than US $\$ 5,000$ (Gargouri et al 2010). However, the notion of paying to be published has raised many ethical concerns. Globally, close to $40 \%$ of researchers are not supported by grants (Mabe 2012), which has resulted in junior academics finding it difficult to acquire tenure and/or promotion (Williams-Jones et al 2014). With gold open access, funds will need to be created to enable these academics to publish their research (Mabe 2012), at a cost of approximately $£ 70$ million a year worldwide with the current levels of adoption (Price 2012).

However, the biggest issue is that, over the years, a number of illegitimate, 'predatory' gold open access journals have emerged for the sole purpose of collecting APCs, which often can be exorbitantly high (Straumsheim 2013). Their peer review processes appear to be a sham, with most manuscripts published without revisions as they have no editorial boards and reviewers are not elicited to review manuscripts (Straumsheim 2013). In an attempt to distinguish credible from predatory gold open access journals, several organisations have collectively drafted a document on best practice (Committee on Publication Ethics et al 2013).

\section{Green open access}

The number of issues associated with gold open access has spurred a 'self-archiving' approach known as 'green' open access to emerge (Swan 2006, MacMillan et al 2014). Green open access means that only the archive pre-print and post-print can be archived. Due to copyright restrictions, the general public cannot have access to the final published version of a manuscript. By uploading their articles to their own websites or to other online repositories, researchers make freely available to researchers and the public articles that they have had published in traditional journals (Gargouri et al 2010). The APC is not incurred by the author but has already been paid by the journal in which it was published (Gargouri et al 2010), so most journals retain the copyright on this material (Coleman 2007).

Although most journals (90\%) explicitly permit authors to self-archive their final submitted manuscripts after peer review (Swan 2006), and loading an article onto a website or institution's repository takes just ten minutes on average (Swan 2006), only a quarter of all articles 
are self-archived every year (Gargouri et al 2010). This may be due to a lack of understanding of open access publishing and/or the failure to recognise the various forms and options available. Scholars have frequently argued that research institutions should have an interest in using their own repositories for 'hosting, archiving, monitoring, measuring, managing, evaluating, and showcasing' the research output of their researchers, as well as in maximising its uptake, usage and impact (Gargouri et al 2010).

Within two years of institutions adopting mandatory self-archiving, 100\% compliance occurs (Gargouri et al 2010). Thus, mandating open access self-archiving adds visibility and value for individuals and institutions.

\section{Conclusion}

In the current academic environment, which is characterised by increased pressures to publish and very low funding success rates, it is difficult to understand why gold open access still exists. Green open access serves to enhance the visibility of an academic's work, as increased downloads of articles tend to lead to increased citations (Swan 2006). Furthermore, as repositories become established, institutions should begin to advocate for their use among the research communities. Researchers should be able to see their articles being downloaded from their institutional repositories and have the assurance in knowing that their work is gaining an increased readership.

In essence, green open access serves to enable access to the research literature, while minimising costs and associated risks. Green is the cheaper option, as well as the most beneficial choice, for universities that want to provide unrestricted access to all literature at minimal risk.
Online archive

For related information, visit our online archive and search using the keywords

Conflict of interest None declared

\section{References}

Coleman A (2007) Self-archiving and the copyright transfer agreements of ISI-ranked library and information science journals. Journal of the American Society for Information Science and Technology. 58, 2, 286-296. Committee on Publication Ethics, the Directory of Open Access Journals, the Open Access Scholarly Publishers Association et al (2013) Principles of Transparency and Best Practice in Scholarly Publishing. tinyurl.com/ m5rj5fn (Last accessed: June 8 2015.)
Gargouri Y, Hajjem C, Larivière V et al (2010) Self-Selected Or Mandated, Open Access Increases Citation Impact For Higher Quality

Research. tinyurl.com/nr78gwd (Last accessed: June 82015 .

Mabe M (2012) Gold Standard Just Right In The 'Goldilocks Zone'. tinyurl.com/cm2akw5 (Last accessed: June 82015.
MacMillan M, Gibb K, Hayman R et al (2014) Dirty Secrets Revealed: Journal Publishing And Marketing, Impact Factors And Access To Scholarship. tinyurl.com/q5enaxg (Last accessed: June 8 2015.)

Price D (2012) Don't Deal In A Debased Currency - Go Green. tinyurl.com/cm2akw5 (Last accessed: June 8 2015.)

Straumsheim C (2013) Principles Of Transparency. tinyurl.com/qfgejem (Last accessed: June 8 2015.)
Swan A (2006) The culture of open access: researchers' views and responses. In Jacobs N (Ed) Open Access: Key Strategic, Technical and Economic Aspects. Chandos Publishing, Oxford.

Williams-Jones B et al (2014) Ethical Challenges of Open-Access Publishing. tinyurl.com/ p5652d6 (Last accessed: June 8 2015.) 